\title{
Algebraforståelse blant studentene i brukerkurs i matematikk ved UiT
}

\author{
E. Malyutina, Ø. Søvik, H.L. Huru \\ Institutt for matematikk og statistikk, UiT Norges arktiske universitet
}

\begin{abstract}
ABSTRAKT: Ved Institutt for matematikk og statistikk, UiT Norges arktiske universitet ble brukerkurset i matematikk høsten 2020 lagt om til et prosjektbasert emne med ny eksamensform. I denne sammenheng har vi valgt å kartlegge ferdigheter og forståelse i algebra i begynnelsen av semesteret, og se nærmere på hvordan studentene videre møter de algebraiske aktivitetene i prosjektene. I denne artikkelen rapporterer vi på resultater fra en pre- og en posttest blant studentene i emnet høst 2020 og drøfter algebra i de obligatoriske prosjektene.
\end{abstract}

\section{INTRODUKSJON}

Ved UiT Norges arktiske universitetet er brukerkurset i matematikk et tilbud til studenter som $\varnothing$ nsker å tilegne seg grunnleggende matematiske ferdigheter til bruk i sitt videre studier og yrkesliv, og bygger på matematikkunnskaper tilsvarende Matematikk R1 eller 2MX/2MN. Studentene som tar emnet kommer fra svært forskjellige studieprogram, men nesten alle er tilknyttet et bachelor/masterprogram i et MNT-fag (matematisk-naturvitenskapelige og teknologiske fag). Høsten 2020 ble brukerkurset i matematikk lagt om til et prosjektbasert emne med mappevurdering og avsluttende muntlig gruppeeksamen. Prosjektoppgavene var tenkt som en mer aktiv læringsform. Med stor vekt på tverrfaglige matematikkoppgaver med anvendelser i fysikk, kjemi, økonomi og biologi, ble studentene utfordret til å bruke sin matematikkunnskap i nye situasjoner, selv innhente kunnskap og samarbeide i grupper. Hensikten var at de tverrfaglige prosjektene og emnet som helhet skulle oppleves mer yrkesrelevant for studentene samt gi positive ringvirkninger til videre studier.

Det forventes at studentene har grunnleggende algebraferdigheter i brukerkurset i matematikk. Da emnet er en grunnsten i studentenes videre studier og fremtidige MNT-fag vil det være interessant å se på hvordan studentene møter algebra gjennom brukerkurset. For å kunne gi et emne bedre tilpasset studentgruppen er det også nyttig å vite mer om studentenes kunnskapsgrunnlag. Vi vil presentere utvalgte resultater fra en pre- og en posttest knyttet til algebra blant studentene i emnet høst 2020 og drøfte disse opp mot litteratur om forståelse i matematikk. Vi vil i lys av teori om algebraiske læringsaktiviteter drøfte algebra i de obligatoriske prosjektene, rapportere på studentenes gjennomføring på spesifikke deler av prosjektene som ligger tett opp til testene. Vi vil til slutt presentere det vi til nå kan rapportere av endringer fra pre og post-testene.

\section{TEORETISK GRUNNLAG}

Som teoretisk grunnlag støtter vi oss på teoriene til Skemp [2] som kategoriserer matematikkforståelse i to typer: relasjonell og instrumentell. Instrumentell forståelse beskrives som «rules without reason», mens relasjonell forståelse danner konseptuell struktur for faget. Skemp [2] sammenlikner disse to typene matematikkforståelse med utforskningen av en by. Når man lærer seg faste ruter mellom bestemte mål og må forholde seg kun til disse danner man instrumentell forståelse, mens når man kan gå fritt rundt i byen og på eget initiativ tar nye veier mellom målene, danner man et kognitivt kart over byen og relasjonell forståelse.

I denne artikkelen anser vi algebra som mer enn symbolmanipulering. I analysen av algebra i prosjektene bygger vi på Kieran [1] som valgte å fokusere på algebra som en aktivitet da hun utviklet GTG-modellen. Modellen gir en mer utdypende beskrivelse av algebra som en aktivitet, hvor aktivitetene deles opp i genererende, transformerende og globale aktiviteter/aktiviteter på metanivå (Generational - Transformational - Global/Meta Level). Genererende aktiviteter i denne modellen involverer danning av uttrykk, variabler og likninger som objekter i algebra og disse objektene generaliserer og representerer problem situasjoner. Genererende aktivitet er et område hvor algebra spiller en rolle som et språk for å uttrykke matematiske betydninger. Transformerende aktiviteter, også kalt regel-baserte aktiviteter, er for eksempel å løse likninger, å samle like ledd, å addere eller 
multiplisere polynomuttrykk, forenkle uttrykk, sette inn tallverdier i utrykk med flere. Globale aktiviteter/aktiviteter på metanivå i algebra innebærer mer generelle matematiske aktiviteter, hvor konteksten spiller stor rolle. Metanivå-aktiviteter inkluderer problemløsing, modellering, arbeid med mønstre, bevis og prediksjoner.

\section{METODE}

Vi har basert vår analyse på to typer data; pre-/posttest og data fra prosjektene, med datainnhenting fordelt over tre tidspunkter i semesteret. I starten av semesteret fikk studentene en kartleggingsprøve, (pretesten). Underveis i semesteret arbeidet studentene med algebraiske aktiviteter tilknyttet prosjektene, og uken før eksamen gjennomførte studentene kartleggingsprøven på nytt (posttesten).

Oppgavene i kartleggingstesten ble konstruert blant annet med den hensikt å avsløre om feil algoritme anvendes. Oppgavene varierte mellom flervalgsoppgaver og åpne/lukkede oppgaver med åpne felt for svar/utregning. Typiske feilsvar legges inn i flervalgsoppgavene og er inspirert av åpent tilgjengelige Algebra Consept Inventory ${ }^{1}$.

Kartleggingsprøven bestod av 15 oppgaver, der 8 av dem var flervalgsoppgaver. Tematisk testet oppgavene brøkregning, potensregning, kvadratsetninger, rasjonale uttrykk, ulikheter, lineære funksjoner og forståelse av operasjoner. I denne artikkelen skal vi fokusere på oppgavene 1, 2, 7, 8 og 14 , som er gjengitt nedenfor.

Fra prosjektene har vi valgt ut den oppgaven som er tettest knyttet til oppgavene studentene ble presentert for i kartleggingstesten. Oppgaveteksten er gjengitt nedenfor.

\section{RESULTATER}

\subsection{Kartleggingstest i algebra}

I begynnelsen av semesteret høsten 2020 fullførte 85 studenter i brukerkurs i matematikk kartleggings/pretesten i algebra med et gjennomsnitt på 41,1\% riktig besvarte oppgaver. Studentene med R2 som matematikkbakgrunn fikk i snitt 51,3\%, de med R1 - 37,1\% og de med S2 - 36\%.

I tabellene nedenfor presenterer vi utvalgte oppgaver fra pretesten, og resultatene på disse.

Tabell 1. Oppgavene 1,2,7,8 fra pretesten om brokregning og rasjonale uttrykk

\begin{tabular}{|c|c|}
\hline Oppgave 1 & $\begin{array}{c}\text { Oppgave 2 (flervalgsoppgave) } \\
\text { Uttrykket } \frac{5}{3} \cdot \frac{7 \cdot 3+3 \cdot 5}{2} \text { kan forenkles til }\end{array}$ \\
\hline Oppgave 7 & a) 65 b) 55 c) 30 d) $\frac{108}{10}$ \\
\hline Trekk sammen og foreta forenklinger & Oppgave 8 \\
$\frac{5}{5-x}+\frac{1}{x+1}$ & Trekk sammen og foreta forenklinger \\
& $\frac{\frac{1}{a+1}+\frac{1}{a^{2}-1}}{a-1}-2 \frac{1}{a+1}$ \\
\hline
\end{tabular}

Tabell 2. Resultater på oppgaver om brøkregning og rasjonale uttrykk

\begin{tabular}{|c|c|c|c|c|}
\hline & Oppgave 1 & Oppgave 2 & Oppgave 7 & Oppgave 8 \\
\hline Fors $\varnothing \mathrm{kt}$ & $100,0 \%$ & $94,1 \%$ & $82,3 \%$ & $61,2 \%$ \\
\hline Riktige & $88,2 \%$ & $82,4 \%$ & $29,4 \%$ & $14,1 \%$ \\
\hline
\end{tabular}

\footnotetext{
${ }^{1}$ http://www.math.utah.edu/ jasonu/aci.pdf
} 
Vi ser at alle studentene har fors $\varnothing \mathrm{kt}$ å $1 \varnothing s e$ den første oppgaven om enkel brøkregning og mesteparten har løst den riktig. Resultatene synker noe på oppgave 2, som krever at studentene bruker flere regneoperasjoner for å komme i mål. Denne trenden fortsetter i oppgave 7 og 8; resultatene synker når oppgavene inneholder rasjonale utrykk og brudden brøk som krever ikke bare antar kjennskap til, men gjentatt bruk av kvadratsetningene.

Oppgave 14 introduserte studentene for en ukjent operasjon, $a \# b=\frac{b}{a}+\frac{a}{b}$, og ba studentene anvende denne operasjonen til å regne ut et uttrykk tilsvarende 1 \# (2 \# 3). Analysen av studentenes løsninger av denne oppgaven ble delt i to steg: det første steget handlet om å forstå og anvende \# operasjonen, mens det andre steget var selve brøkregningen og å få trukket sammen uttrykket riktig. Overraskende mange studenter forstod betydningen av den ukjente operasjonen \#, og klarte å sette opp uttrykket riktig. Derimot ble den påfølgende brøkregningen, som krevde god forståelse for brudden brøk, utfordrende for studentene.

Tabell 3. \#-oppgaven.

\begin{tabular}{|c|c|c|}
\hline & Oppsett med \#-operasjon & Utregninger \\
\hline Forsøkt & $56,5 \%$ & $60 \%$ \\
\hline Riktige & $51,7 \%$ & $10,6 \%$ \\
\hline
\end{tabular}

Resultatene tyder på at en stor andel av studentene i gjenkjennelige situasjoner - som i vanlig brøkregning - viser tydelige tegn på instrumentell forståelse: Studentene mestrer godt oppgaver med enkel brøkregning som i oppgavene 1 og 2 , men i møte med mer kompliserte rasjonale uttrykk som i oppgavene 7 og 8 kommer kunnskapen til kort. Studentene prøver med varierende hell ulike oppskrifter som «felles nevner», «trekk sammen», «forkort» osv. Imidlertid, når brøk opptrer i en ny og ukjent situasjon som \#-operasjonen i oppgave 14 ser vi tegn på relasjonell forståelse, og at studentene i større grad klarer å kunne anvende eksisterende kunnskap. Samtidig, i samme oppgave 14, når det kommer til å regne ut brøkuttrykket, fullfører studentene igjen de kjente prosedyrene med varierende hell og rekkefølge. Foreløpig tolker vi resultatene dithen at studentene som viser gode evner i problemløsing, blir for opptatt av oppskrifter i møte med kjente oppgaver til å klare å løse mer kompliserte rasjonale uttrykk.

Vi vil kommentere at forhold til GTG-modellen kan alle oppgavene i kartleggingstesten vi her refererer til kategoriseres som transformerende. Det eneste unntaket er bruk av \#-funksjonen som vi tolker som en aktivitet på metanivå.

\subsection{Algebra i prosjektoppgavene}

Kartleggings-/pretesten inneholdt oppgaver i kjent drakt, der studentene kunne anvende kjente regler og følge oppskrifter de var vant med fra tidligere. Prosjektoppgavene var derimot av en mer utforskende natur og inneholdt en stor del problemløsning av tverrfaglige matematikkoppgaver. Oppgavene var med vilje utformet slik for å motivere studentene til å tenke selv, lete opp informasjon fra flere kilder og anvende kunnskaper og ferdigheter de besitter i nye og ukjente situasjoner.

Ett $\emptyset$ nske er altså at studentene skal møte matematikk på en annen måte enn det for eksempel Wæge \& Nosrati [3] beskriver at er typisk i matematikklasserom i Norge: "Det legges stor vekt på vise hvordan man finner det riktige svaret, og oppgavene elevene arbeider med er ofte like i strukturen (om ikke identiske). A vite hvorfor og det å se sammenhenger får mindre oppmerksomhet." Denne arbeidsformen og puggingen danner ifølge Skemp [2] instrumentell forståelse av matematikk. I prosjektene var ikke oppgavene rent algebraiske eller kun symbolmanipulasjon, men de algebraiske aktivitetene måtte brukes mer intuitivt i ekte situasjoner og i møte med andre deler av matematikken, og dermed være en mulighet for å danne mer relasjonell forståelse i algebra hos studentene.

Når en sammenligner resultatene på pretesten og nivået av algebraferdigheter nødvendig for å fullføre prosjektene, er det et tilsynelatende sprik. Flere oppgaver i prosjekt 1 krevde algebraferdigheter utover det elementære for å løses. Under drøfter vi disse oppgavene i lys av GTG-modellen [7] og studentenes besvarelser. Generelt var alle oppgavene i prosjektene basert på metanivå-aktiviteter satt i en praktisk kontekst. Vi har valgt ut enkelte deloppgaver fra en oppgave om Fibbonacitall, som er den delen av prosjektene som ligger tettest opp mot kartleggingstesten og dermed etter vår mening gir best grunnlag 
for sammenlikning. Oppgaven begynner med observasjon av plantearter som produserer blomster (studentene gjør et fritt valg fra internett eller andre kilder). Studentene bes om å utforske sammenhengen mellom antall kronblad og Fibonaccitall. Videre introduseres Fibonaccitallene som $F_{n}$ med $F_{n+1}=F_{n}+F_{n-1}, F_{1}=1, F_{2}=1$. Etterpå måtte studentene jobbe videre med konstanten $\varphi$, definert som forholdet $\frac{F_{n+1}}{F_{n}}$ når $n$ vokser over alle grenser. I alle de påfølgende delspørsmålene skulle studentene ikke gjøre numeriske beregninger med desimaltall, men eksakte beregninger med brøk og kvadratrøtter.

i) Vis at konstanten $\varphi\left[=\frac{F_{n+1}}{F_{n}}\right]$ er en losning til likningen $\varphi=1+\frac{1}{\varphi}$.

j) Verifiser at den eneste positive lфsningen til denne likningen er $\varphi=\frac{1+\sqrt{5}}{2}$.

Vis at den andrelфsningen, $\psi$, er gitt ved $\psi=\frac{1-\sqrt{5}}{2}$ og at vi har sammenhengen $\psi=-\frac{1}{\varphi}$.

k) La a og b vare vilkårlige reelle tall og definer for $n=0,1,2,3, \ldots, G_{n}=a \varphi^{n}+b \psi^{n}$

Vis ved direkte regning at dersom $a=\frac{5+\sqrt{5}}{20}$ og $b=\frac{5-\sqrt{5}}{20}$

så er $G_{1}, \ldots, G_{4}$ alle rasjonale tall.

l) Vis ved direkte regning at $\left(\frac{1+\sqrt{5}}{2}\right)^{2}=\frac{1+\sqrt{5}}{2}+1$ og bruk dette til å vise at vi har $\varphi^{n+1}=\varphi^{n}+\varphi^{n-1}$ for alle $n$.

Vi plasserer oppgavene i), j), k) og første del av l) alle under transformerende aktiviteter ifølge GTGmodellen [1], da de alle er baserte på algebraiske utregningsregler. Siste del av oppgave 1), og til dels oppgave i), tolker vi som en aktivitet på metanivå der studentene må bruke sin kunnskap til å utføre et bevis. Denne siste oppgaven er så pass utfordrende ut fra studentenes nivå at vi mener den i stor grad blir av utforskende/problemløsende natur.

For dette prosjektet var studentene delt inn i 61 grupper med opptil tre studenter i hver gruppe og 51 av disse leverte inn en besvarelse. Oppgave i) klarte 11 grupper av $51(21,6 \%)$, mens $23(45,1 \%)$ grupper kom i de tidligere deloppgavene fram til forholdet mellom to påfølgende Fibonaccitall når $n \emptyset$ ker, $\varphi$, som et desimaltall, og at dette desimaltallet er løsningen til likningen i i). Dermed ble det vanskelig for studentene i disse 23 gruppene å løse oppgaven og de kunne heller ikke generalisere Fibonaccitallene ved bruk av likningen. I oppgave j) klarte 33 av 51 grupper $(64,7 \%)$ å verifisere at den eneste positive løsningen til likningen var $\varphi=\frac{1+\sqrt{5}}{2}, 2$ grupper brukte CAS (Computer Algebra System) for å løse likningen, mens 5 grupper satt inn et desimaltall for $\varphi$ i likningen og viser at likningen stemmer. Videre klarte 21 av 51 grupper $(41,2 \%)$ å vise riktig ved bruk av brøkregning og regning med kvadratrøtter at $\psi=-\frac{1}{\varphi}$, mens 16 grupper brute desimaltallsutrykk for både $\varphi$ og $\psi, 2$ grupper brukte CAS, og 3 grupper mangler mellomregninger.

Oppgave k) var fullført riktig av 27 grupper (52,9\%) med alle mellomregninger. 11 grupper fant riktig svar, men viste ikke fremgangsmåte. 3 grupper brukte enten CAS eller nettbasertkalkulator, og 4 grupper regnet ut $G_{1}, \ldots, G_{4}$ ved bruk av desimaltall. 38 av 51 grupper $(74,5 \%)$ klarte å vise ved direkte regning formelen for $n=1$ i oppgave 1), 4 grupper brukte enten CAS, en nettbasertkalkulator eller brukte desimaltallutrykk for å vise at formelen stemmer. Å bevise at formelen i oppgave 1) stemmer for alle $n$ klarte 10 av 51 grupper riktig $(19,6 \%), 19$ grupper viser at formelen stemmer for noen bestemte $n$ (= $1,=2, \ldots)$ og konkluderte at formelen stemmer for alle $n$.

Oppsummert er det i gjennomsnitt 45,8\% av disse algebraoppgavene i denne prosjektoppgaven som var gjort riktig ved direkte utregninger og riktige fremgangsmåter, og viser dermed ett bedre resultat enn pretesten. I tillegg er det en stor del av studentene som tilsynelatende forstår oppgaven, men enten bruker desimaltall eller digitale verktøy for å få til de algebraiske operasjonene. Vi tolker det slik at studentene får vist mer av sine matematiske ferdigheter når de får bedre tid til å tenke over oppgavene, tilgang til forskjellige læringsressurser og mulighet for samarbeid. Vi ser også at studentene klarer mer kompliserte operasjoner enn i kartleggingstesten og løser likninger på former de ikke er vant til fra videregående 
skole. Imidlertid er det vanskelig å si, bare ut ifra prosjektene, om studentene har fått et lite hint fra hjelpelærer eller andre.

Det bemerkes at flere studenter bruker CAS eller liknende for å gjennomføre oppgavene som krever direkte utregninger. Forskningen til Saldana og Kieran i 2005 (sitert i [1], s. 732) viser at mest produktiv læring skjer når utregninger i CAS kommer i konflikt med studentenes forventninger. Et eksempel er oppgave k) der studentene kan få irrasjonelle tall for $G_{1}, \ldots, G_{4}$, mens CAS gjør dem om til brøkuttrykk med heltall i teller og nevner. Samtidig hevder Warren og Pierce (sitert i [1], s. 738) at produktiv bruk av CAS er avhengig av visse ferdigheter for hånd: løse enkle likninger, bruke grunnleggende algebraiske manipulasjoner, omskrive likninger til en form slik at de kan brukes og være bevisst standardteknikker for å finne løsninger.

\subsection{Resultater av posttesten}

I midten av november ble samme karleggingstest $\mathrm{i}$ algebra gjennomført på nytt, denne ble delt ut $\mathrm{i}$ regnetimene $\mathrm{i}$ de siste to ukene med undervisning. Det var 22 studenter som gjennomførte denne posttesten, hvorav ytterlige 6 studenter måtte ekskluderes da de ikke hadde gjennomført kartleggingsprøven ved semesterstart. Gjennomsnittet for disse 16 studentene sank fra 50\% til 44,8\% riktig. Det er vanskelig å tolke resultatene da vi ikke har et representativt utvalg for studentene i brukerkurset. Vi vil bemerke at da vi skulle gjennomføre posttesten kom det en oppblomstring av korona i Troms $\varnothing$, samt at studentene fikk beskjed om omlegging av eksamen til digital hjemmeeksamen og vi tror dette reduserte tilstedeværelsen blant studentene.

\section{KONKLUSJONER OG VEIEN VIDERE}

Semesteret høst 2020 var en pilot for brukerkurset i matematikk som proskjektbasert emne. Fra resultatene tolker vi at studentene viser forbedring i algebraferdigheter på prosjektene sammenliknet med pretesten, men det samme ser vi ikke på posttesten. Resultater av posttesten er vanskelig å dra noen konklusjoner fra, da utvalget av studenter var for knapt til å være representativt. I tillegg kan studentene ha vært mindre motiverte til å gjøre det bra på en slik test, sammenlignet med prosjektene som var relevant for eksamen. På prosjektene er det vanskelig å avgjøre hvilken type matematikkforståelse som ligger til grunn, da relasjonell og instrumentell forståelse kan gi tilsynelatende like besvarelser, jf. [2]. En gruppe kan virkelig ha forstått begrepene og opparbeidet seg har relasjonell forståelse, mens en annen den kan ha anvendt sin verktøykasse med «rules without reason» sammen med eksempler fra internett eller kalkulatorer som viser stegvis utregning. Videre er det vanskelig å trekke klare konklusjoner fra resultatene på prosjektene da studentene arbeidet gruppevis, og ikke individuelt. Likevel ser vi en klar trend til at studentene angriper tekstoppgavene i de tverrfaglige prosjektene bedre enn vi så i kartleggingstesten.

Vi forventet at omleggingen av emnet og algebraiske aktiviteter [1] i prosjektoppgavene kunne stimulere til $\varnothing \mathrm{kt}$ relasjonell forståelse blant studentene i emnet. Kan man si studentenes relasjonelle forståelse har $\emptyset \mathrm{kt}$ ? Det er vanskelig å dra noen klare konklusjoner når resultatene fra posttesten ikke er representativt. Imidlertid, klarer studentene tilsynelatende krevende tekstoppgaver på prosjektene "når det tells" - og viser ett høyre nivå av algebraferdigheter enn det vi så i kartleggingstesten. Det å kunne møte nye ukjente situasjoner med de kunnskapene og ferdighetene man har med seg håper vi uansett vil ha betydning ut over matematikkfaget, som generell livsmestring og i fremtidig yrke og fag.

\section{REFERANSER}

[1] Kieran, C. (2007). Learning and teaching algebra at the middle school through college levels, Building meaning for symbols and their manipulation, Second handbook for research on mathematics teaching and learning, pp. 707-762.

[2] Skemp, R.R. (2006), Relational Understanding and Instrumental Understanding, Mathematics Teaching in the Middle School, Vol. 12, No. 2, pp. 88-95.

[3] Wæge, K. \& Nosrati, M. (2015), Sentrale kjennetegn på god læring og undervisning i matematikk, Utdanningsforskning.no. Hentet fra: https://utdanningsforskning.no/artikler/sentrale-kjennetegn-pa-godlaring-ogundervisning-i-matematikk/ (11.12.2020) 